\title{
UNIVERSAL LANGUAGE FOR COMPUTING MACHINES
}

$\mathrm{T}$ HE traditional pattern of Section A* (Mathematics) meetings at the British Association, consisting of a division into pure and applied mathematical sessions, was this year preserved with a difference.

On September 1 at Norwich the 'pure' session opened with a paper by Prof. R. L. Goodstein having the title "Truth Tables". Starting with a simple account of formal mathematical logic Prof. Goodstein showed how the apparently 'basic' operations and, or, not, etc., could successively be reduced to a single pair and, eventually, to the single 'Sheffer stroke' function. The talk was a model of systematic presentation and took the audience from the elements to up-to-date research in the field of multi-valued logies.

In the discussion which followed it was made clear that this very 'pure' subject had considerable practical application, particularly as the Sheffer function gives a means for constructing the most complex digital computer from a single type of building block.

The second paper, by Prof. P. J. Hilton, was concerned with group theory and showed how the basic ideas of elementary arithmetic might better be taught via this fundamental discipline than by the present rote-learning methods.

To conclude this session, a paper by Dr. P. F. Scott described the characteristics of the various kinds of radio telescope. After showing that any large increase in size over the instrument at Jodrell Bank was impossible, he went on to show that, by using relatively small movable aerials of simple geometry, and by making the rotation of the Earth act as a scanning mechanism, the effect of receiver areas of several acres could be simulated. The catch was, that to obtain a picture of the heavens of the type used by astronomers, it was necessary to use a digital computer to process the 250,000 or so observations. Thus the first session ended with a distinct flavour of computers.

On September 5, there was a symposium on artificial computer languages. Mr. P. V. Ellis, of International Computers and Tabulators, Ltd., opened the meeting by explaining how, in the early computers, a programme was set into the machine almost by the individual operation of switches which controlled the electronic elements. He pointed out that an operation which took only a few human words to mention might take as many thousands of the code symbols understandable by a computer. From this basis he explained how the notion of a human/machine language for communication arose and described the early attempts at formulating such systems for both mathematical and business use. 'These were, he said, now tending to merge, but difficulties existed because, while the language of mathematics was relatively precise, that of commerce was not, so that the same words might mean quite different things to different people.

To show the three stages of interpretation which are involved, the example of developing a simple statement like : "We wish to take Smith's pay and compute the income tax", into a detailed procedure expressed in words and appropriate mathematical symbols and thence into a detailed machine coding, was analysed. After rejecting the simple solution that accountants and business men should learn mathematics-"because they will not"-current progress in the development of a commercial language 'Cobol' was described. The value of such a language, if accepted, was shown by the fact that, over the life of a machine, the cost of programming was about $1 \frac{1}{2}$ times that of the machine itself.

The theme of commercial computer languages was then taken up by Mr. R. M. Paine, of the Corporation for Economic and Industrial Research. After explaining that about 6,000 electronic computers of various sizes were now in operation, he went on to remark that a computer code such as :

$$
\begin{array}{rrrr} 
& 60 & 6 & 31 \\
25 & 72 & 5 & 34 \\
& 400 & 4 & 17
\end{array}
$$

would be difficult to explain to people unfamiliar with the particular machine concerned-and possibly even to those who were. On the other hand, a statement in 'Cobol' :

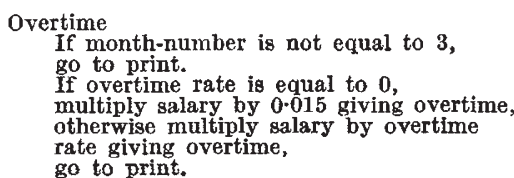

could be understood by all.

'Cobol' was a beginning of an agreed language and was accepted by the producers of some 90 per cent of the world's output of computers. Some other attempts at artificial languages, such as the Ferranti 'Nebula', were mentioned and the paper ended with an account of a modern development whereby computers could directly understand selected words of ordinary language presented to them.

The scientific side of eomputer language was then taken up by Mr. C. Strachey, who suggested that programming was now emerging from its adolescent phase in which an intimate knowledge of the machine, ad hoc tricks, and infinite patience on the part of the programmer were of supreme importance. $\mathrm{He}$ suggested that the two 'new' techniques of greatest future promise were : a function language, and the replacement of the idea of linear sequences of instructions by branched chains in which no attempt was made to maintain natural order, but in which each constituent gave explicit reference to its successors. Having dismissed these topies Mr. Strachey then developed an attack on British computer designers and research workers in the universities and elsewhere. The burden of his discontent was that, whereas the American approach was to use a machine of any cost, however high, to save human effort, the British machines required the use of human genius to help the machine. He ended by claiming that this trouble was caused by the absence of very large random access stores on the British machines.

The last of the formal papers was read by Mr. R. G. Goodman, of the Brighton College of Technology. 
The basic structure of the mathematical 'language' 'Algol' was explained and developed to the state in which a complete problem was coded for illustration.

The discussion was opened by Dr. A. D. Booth, of Birkbeck College, London, who, after commenting on the implication of Mr. Ellis's figure of $1 \frac{1}{2}$ for programming/machine cost, pointed out that $\mathrm{Mr}$. Strachey's strictures were, to a large extent, unjust. The ideas of function languages were well known in Great Britain and much work has been done in them. The branched chain têchnique had been in use at
Birkbeck College for at least three years and was described in several papers so that a claim that "no one in Britain had experience of it" was patently false. So far as lack of large, random-access, stores on British machines was concerned, Dr. Booth maintained that far from being due to lack of imagination, the situation was actually caused by lack of Government support for British machines.

A vigorous discussion, in which the topics ranged from qualifications and training of programmers to the various kinds of 'meta-language' in machine translation, ended the session.
A. D. Воотн

\title{
PHILOSOPHICAL TRANSACTIONS OF THE ROYAL SOCIETY
}

\author{
By DR. W. P. D. WIGHTMAN
}

Department of History and Philosophy of Science, King's College, University of Aberdeen

T HE spate of publications relating to the Royal Society of London during the past two years seems to have increased rather than diminished the already existing misunderstanding of the relation between the Society and the famous periodical which it encouraged, but for which on several occasions the Society published or caused to be published disclaimers for any responsibility. Recently, references have been made to volumes of the Philosophical Transactions of the Royal Society (sometimes with 'of London' added) in the seventeenth century, when no periodical with this title existed; statements have been made (or implied) that there was only one (or no) interruption in its publication; and, worst of all, that it was the 'official' journal of the Royal Society. The precise title would perhaps not be of any serious import but for the fact that the inclusion of the words 'of the Royal Society' suggests that it was a record of the 'Transactions' of that body and hence gives plausibility to the term 'official'. Since statements about the Philosophical Transactions (a few incorrect, and others by condensation definitely misleading) are scattered about over a large number of recent articles, it seemed desirable to assemble a sufficient number of 'advertisements' by the Society or its officers to establish the facts relating to the Philosophical Transactions. The purpose of this article is thus primarily bibliographical in the broad sense: it is not concerned with the purpose or quality of the Transactions. It is basod on an examination (though, of course, far from exhaustive) of every volume of the Transactions (and Philosophical Collections to be referred to below) in the first two centuries of its existence.

The title on the first number issued and on the title page of every subsequent volume until Vol. 66 of 1776 was: "Philosophical Transactions: giving some accompt of the present undertakings, studies, and labours of the Ingenious in many considerable parts of the world".

There is no mention of the Royal Society other than in the imprint of its printers, John Martyn and James Allestry, and in Oldenburg's dedicatory epistle. Moreover, there is a clear indication that the editor and publisher had cast his net widely to get a representative review: the result was in fact a great deal more like Nature than a mere organ of publication of individual researches. But, despite this clear indication, confusion must have arisen at so early a date as to require the following disclaimer to be published in No. 12 of May 1666: "Whereas 'tis taken notice of that several persons perswade them. selves that these Philosophical Transactions are publish't by the Royal Society, notwithstanding many circumstances to be met with in the already publish't ones that import the contrary: the Writer thereof hath thought fit, expressly here to declare that that perswasion, if there be any such indeed, is a mere mistake. . . . Though he denios not, but that having the honour and advantage of being a Fellow of the said Society, he inserts at times some of the Particulars that are presented to them".

The last number of the Transactions in the first run was dated February 1679 . From some time in the same year (colophon of first number) to April 1682 their place was taken by Robert Hooke's Philosophical Collections "containing an account of such physical, anatomical, ... or other mathematical and philosophical experiments and observations as have lately come to the publisher's hands. As also an account of some books of this kind lately published". A similar 'advertisement' was printed in the number of December 1681. The Philosophical Transactions recommenced in January 1683 with the preface: "Although the writing of these Transactions is not to be looked upon as the Business of the Royal Society, yet in regard they are a Specimen of many things which lie before them. . . They have thought fit to take care for the revival thereof. . . ." Vol. 16 contained the numbers issued during 1686 and 1687 and bore the imprint "London 1688" (some previous volumes were printed at Oxford "at the [Sheldonian] Theater"). Thereafter, publication was suspended until early in 1691 "chiefly by reason that the unsettled posture of publick affairs did divert the thoughts of the curious towards matters of more immediate concern than are physical and mathematical enquiries. . .." These were, of course, the years of the 'Glorious Revolution', and this gap in the Transactions has been overlooked in some accounts.

It is not possible, nor indeed necessery, to cite every declaration of editorial policy : all call the same tune with variations $\rightarrow$ review of what is going on in the world of 'philosophy', including "an exact account of such experiments as having been made before the 